\title{
Active Thermochemical Tables: dissociation energies of several homonuclear first-row diatomics and related thermochemical values
}

\author{
Branko Ruscic · David Feller · Kirk A. Peterson
}

Received: 5 September 2013/Accepted: 23 October 2013/Published online: 22 November 2013

(C) The Author(s) 2013. This article is published with open access at Springerlink.com

\begin{abstract}
The current Active Thermochemical Tables (ATcT) results for the bond dissociation energies of the homonuclear diatomics $\mathrm{H}_{2}, \mathrm{C}_{2}, \mathrm{~N}_{2}, \mathrm{O}_{2}$, and $\mathrm{F}_{2}$ are reported and discussed. The role and origin of the distributed provenance of ATcT values is analyzed. Ramifications in terms of the enthalpies of formation of $\mathrm{H}, \mathrm{C}, \mathrm{N}, \mathrm{O}$, and $\mathrm{F}$ atoms, which are fundamental thermochemical quantities, are presented. In addition, the current ATcT bond dissociation energies and enthalpies of formation of $\mathrm{HF}, \mathrm{CH}, \mathrm{CO}, \mathrm{CN}, \mathrm{NO}, \mathrm{OH}, \mathrm{CO}_{2}$, $\mathrm{H}_{2} \mathrm{O}$, and triplet and singlet $\mathrm{CH}_{2}$ are also reported.
\end{abstract}

Keywords Enthalpy of formation .

Thermochemical network · Theory-experiment interface $\cdot$ Benchmark values

\section{Introduction}

Active Thermochemical Tables (ATcT) [1, 2] are a novel paradigm for obtaining accurate, reliable, and internally

Dedicated to Professor Thom Dunning and published as part of the special collection of articles celebrating his career upon his retirement.

B. Ruscic $(\bowtie)$

Chemical Sciences and Engineering Division, Argonne National Laboratory, Argonne, IL 60439, USA

e-mail: ruscic@anl.gov

B. Ruscic

Computation Institute, University of Chicago, Chicago,

IL 60637, USA

D. Feller · K. A. Peterson

Department of Chemistry, Washington State University,

Pullman, WA 99164, USA consistent thermochemical values for a broad range of chemical species, accompanied by statistically sound uncertainties that conform to the accepted standard in thermochemistry (95\% confidence intervals). These characteristics of the ATcT thermochemical values make them very desirable for developing and benchmarking highly accurate state-of-the-art electronic structure approaches [3-6].

In a companion paper [7], the Feller-Peterson-Dixon (FPD) procedure at the highest currently feasible computational level is applied to $\mathrm{H}_{2}$ and 13 small first- and second-row molecules, and the results are compared to dissociation energies obtained from ATcT. The aim of the current paper is to report the current ATcT values for the bond dissociation energies of $\mathrm{H}_{2}, \mathrm{C}_{2}, \mathrm{~N}_{2}, \mathrm{O}_{2}$, and $\mathrm{F}_{2}$ and elucidate their provenances.

Gas-phase homonuclear diatomics of hydrogen, nitrogen, oxygen, and fluorine are the thermodynamic reference states for the corresponding elements. Their dissociation energies are tightly related to the enthalpies of formation of the corresponding atoms, which are fundamental thermochemical quantities that belong to the CODATA 'key' set [8]. Since the CODATA evaluation, these quantities have gained additional relevance: the availability of accurate and reliable values for enthalpies of formation of atoms has become a sine qua non for electronic structure methods that use the total atomization energy route to obtain practical enthalpies of formation.

\section{The approach of Active Thermochemical Tables}

As opposed to traditional thermochemistry, which uses a sequential approach to build a set of thermochemical values (A begets B, B begets $\mathrm{C}$, and so on), ATcT are based 
on constructing, analyzing, correcting, and solving a thermochemical network (TN) [1,2]. The TN contains the available experimental determinations that thermochemically interconnect the targeted chemical species (such as bond dissociation energies, reaction enthalpies, constants of equilibria, ionization energies, and electron affinities), complemented by similar determinations extracted from high-level theoretical calculations (such as energies of various isodesmic reactions, bond dissociation energies, and total atomization energies). Each determination in the $\mathrm{TN}$ has an initially assigned uncertainty, reflecting its perceived $95 \%$ confidence interval. Uncertainties are an important integral component of the $\mathrm{TN}$ : they determine the weight by which each determination contributes to the overall knowledge content of the TN and thus regulate the uncertainties of the final results. After the TN is constructed and checked for stoichiometric correctness, ATcT proceed with an iterative statistical analysis that exploits the available thermochemical cycles in the TN and evaluates all determinations for mutual consistency, producing a ranked list of potential 'offenders,' i.e., determinations with too optimistic uncertainties, which would unduly skew the final results if left uncorrected. The uncertainty of the most likely 'offender' is then augmented by a small increment, and the statistical analysis is repeated until internal consistency is achieved across the entire TN. Once the TN is internally consistent, ATcT obtain the final results by solving it simultaneously for all included chemical species.

The ATcT TN approach provides a number of significant advantages over the traditional sequential approach, described in more detail elsewhere [1, 2, 9, 10]. Because the results are obtained by simultaneously satisfying all relevant determinations present in an internally consistent $\mathrm{TN}$, the ATcT values are not only more accurate, ${ }^{1}$ but also more robust $^{2}$ than those obtained from a sequential approach. A typical sequentially obtained thermochemical value has a critical dependency on the reliability and integrity of the particular determination that was selected for its derivation. In contrast, ATcT values typically have a distributed provenance and thus do not critically depend on the accuracy and reliability of a single determination. In rare cases when the ATcT thermochemistry of some

\footnotetext{
1 The term 'precision' is normally reserved to describe the spread of values (i.e., the width of the distribution), without taking into account the possible bias between the true value and the central value of the distribution, also known as 'trueness.' Occasionally, the term 'accuracy' is used as a synonym for 'trueness.' In the present paper, the term 'accuracy' encompasses the best estimate of both 'trueness' and 'precision,' in keeping with ISO 5725 standard.

2 In the present paper, the term 'robustness' is used only in a qualitative sense and implicates a resistance to change if one of the relevant determinations is removed, or if a new determination of similar quality is added.
}

species displays a strong dependency on a single thermochemical determination, the latter is marked as a 'weak link,' and the corresponding section of the TN is earmarked for fortification by acquiring new experimental and/or theoretical determinations. The distributed nature of the provenance, ${ }^{3}$ together with the fact that all provenance contributors are brought into mutual consistency before computing the final solution, are very important aspects of the ATcT approach that enable ATcT to produce results of superior accuracy and robustness.

The current ATcT TN (ver. 1.118) spans over a thousand chemical species and contains nearly 16,000 determinations. Describing even a modest fraction of these determinations is obviously well outside the scope of any single paper. However, the degree to which each of these determinations contributes to the enthalpy of formation of a given species (or to some other related thermochemical quantity, such as a particular bond dissociation energy) can be evaluated by performing a variance/covariance decomposition. This enables us to focus the discussion only on those determinations that make a prominent contribution to the provenance of the targeted thermochemical quantity.

\section{ATcT results and their discussion}

Since gas-phase $\mathrm{H}_{2}, \mathrm{~N}_{2}, \mathrm{O}_{2}$, and $\mathrm{F}_{2}$ are the thermodynamic reference states for the corresponding elements (having by definition an enthalpy of formation of zero at all temperatures), the enthalpies of formation of the corresponding atoms are exactly equal to half the bond dissociation enthalpy of the homonuclear diatomic molecule. The same, of course, does not hold for $\mathrm{C}_{2}$. For carbon, the thermodynamic reference state is graphite, and thus, the enthalpy of formation of the carbon atom corresponds to the enthalpy of vaporization of graphite to monatomic carbon, while the enthalpy of formation of $\mathrm{C}_{2}$ corresponds to the enthalpy of vaporization of graphite to diatomic carbon. The two are related via the dissociation energy of diatomic carbon. While $\mathrm{C}_{2}$ will be discussed here in pertinent detail, describing the genesis of the ATcT value for carbon atom would require a separate discussion that is outside the scope of the present paper. Nevertheless, for the sake of completeness, the current ATcT enthalpy of formation of C atom is also reported here.

Each of the cases discussed below in more detail is interesting in its own way: (1) $\mathrm{H}_{2}$ is a relatively simple case devoid of complications that allows us to illustrate some of

\footnotetext{
3 'Provenance' is in the present paper used as a quantitative descriptor; the contribution of an arbitrary determination to the provenance of an arbitrary thermochemical quantity is defined numerically as the relative contribution of that determination to the final value of the variance of the thermochemical quantity in question.
} 
the important characteristics of ATcT results; (2) $\mathrm{C}_{2}$ illustrates a case that suffers from a dearth of experimental data; (3) $\mathrm{N}_{2}$ illustrates a case that involves the resolution of a 'weak link' before reliable thermochemistry can be obtained; (4) $\mathrm{O}_{2}$ illustrates a case where one needs to include an often 'forgotten' correction to experimental data in order to achieve the final accuracy; (5) $\mathrm{F}_{2}$ provides a case where the ATcT must use arbitration to resolve inconsistencies between relevant determinations.

\subsection{ATcT values for $D_{0}\left(\mathrm{H}_{2}\right)$ and $\Delta_{\mathrm{f}} H^{\circ}(\mathrm{H})$}

The current ATcT value for $D_{0}\left(\mathrm{H}_{2}\right)$ is $432.068_{06} \pm$ $0.000_{02} \mathrm{~kJ} / \mathrm{mol}$ (see Table 1), or, equivalently, $\Delta_{\mathrm{f}} H^{\circ}{ }_{0}(\mathrm{H})=$ $216.034_{03} \pm 0.000_{01} \mathrm{~kJ} / \mathrm{mol}\left(217.997_{88} \mathrm{~kJ} / \mathrm{mol}\right.$ at $298.15 \mathrm{~K}$; see Table 2). ${ }^{4}$ Other than gradually gaining in accuracy as the TN was expanded over time, these ATcT values have not changed significantly since the previously reported versions [1, 3, 4, 9-11]. The CODATA value [8], subsequently adopted in the popular tables of Gurvich et al. [12,13] and in the JANAF Tables ${ }^{5}[14,15]$, was already quite accurate, $\Delta_{\mathrm{f}} H^{\circ}{ }_{298}(\mathrm{H})=217.998 \pm 0.006 \mathrm{~kJ} / \mathrm{mol}$, and thus in this particular case, the improvement in accuracy by almost three orders of magnitude is probably of no practical thermochemical consequence.

The CODATA value for the enthalpy of formation of $\mathrm{H}$ relies entirely on a single measurement: the $\mathrm{H}_{2}$ dissociation energy of Herzberg [16] (see additional discussion of the CODATA value in Ruscic et al. [1]). In contrast to this, the provenance of the ATcT value is significantly distributed, reflecting a typical outcome of the ATcT TN approach. The first $90 \%$ of the provenance of $\Delta_{\mathrm{f}} H^{\circ}(\mathrm{H})$ and/or $D_{0}\left(\mathrm{H}_{2}\right)$ includes no less than 9 different determinations, and in order to pedigree $99.9 \%$ of the provenance, one needs to include 30 different determinations. The most prominent experimental contributors to the provenance are the determination of the ionization energy of ortho- $\mathrm{H}_{2}$ of Liu et al. [17], their reevaluation of the ionization energy of $\mathrm{H}$ and of the dissociation energy of $\mathrm{H}_{2}{ }^{+}$using the CODATA 2006 constants [18], the evaluation of the ionization energy of $\mathrm{H}$ by Erickson [19]

\footnotetext{
$\overline{4}$ The significant digits in the values given in the text and in Tables 1 and 2 are un-subscripted and correspond either to a maximum of three significant digits after the decimal point or to two significant digits in the related uncertainty (whichever is less); when given, extra digits are subscripted.

5 As opposed to Gurvich et al. [12, 13], who adopted the values from the final CODATA report [8], the third edition of JANAF [14] has adopted a slightly different set of values from an interim report of the CODATA Task Group. The fourth edition of JANAF [15] retains the interim values adopted in the third edition. For $\mathrm{H}$ atom, the value adopted by JANAF is larger by $0.001 \mathrm{~kJ} / \mathrm{mol}$, for $\mathrm{O}$ atom is lower by $0.010 \mathrm{~kJ} / \mathrm{mol}$, for $\mathrm{F}$ atom is larger by $0.010 \mathrm{~kJ} / \mathrm{mol}$.
}

(additionally rescaled to current values of natural constants), the determination of $D_{0}\left(\mathrm{H}_{2}\right)$ by Zhang et al. [20], the evaluation of the same quantity by Stoicheff [21], the determination of para-ortho separation in $\mathrm{H}_{2}$ by Jennings et al. [22], and the determination of the ionization energy of $\mathrm{H}_{2}^{+}$by de Lange et al. [23]. With respect to theoretical contributors, the most prominent contributors are the determinations of $D_{0}\left(\mathrm{H}_{2}\right)$ and of para-ortho separation in $\mathrm{H}_{2}$ by Piszczatowski et al. [24], of the Lamb shift in $\mathrm{H}$ by Johnson and Soff [25], of $D_{0}\left(\mathrm{H}_{2}{ }^{+}\right)$by Moss [26], of paraortho separation in $\mathrm{H}_{2}$ by Schwartz and Le Roy [27], and of $D_{0}\left(\mathrm{H}_{2}\right)$ by Wolniewicz [28] and by Kolos and Rychlewski [29].

The list of provenance contributors attests to the fact that ATcT utilize the knowledge content of available determinations, irrespective of whether they are of experimental or theoretical origin. One also easily notes that in addition to being highly distributed, the provenance does not correspond to a straightforward collection of competing determinations of $D_{0}\left(\mathrm{H}_{2}\right)$, but it includes such species as ortho- $\mathrm{H}_{2}, \mathrm{H}_{2}{ }^{+}, \mathrm{H}^{+}$. These two observations illustrate an important general characteristic of the ATcT approach: the final values have distributed provenances, reflecting the fact that they have been obtained by simultaneously satisfying all statistically relevant determinations through all statistically relevant thermochemical cycles available in the TN.

The determination of $D_{0}\left(\mathrm{H}_{2}\right)$ by Herzberg [16], which provided the CODATA/JANAF/Gurvich value for the enthalpy of formation of $\mathrm{H}$, is included in the $\mathrm{TN}$, but ends up contributing rather negligibly to the final result. The primary reason for this is that it seriously lags in accuracy when compared to the current list of prominent provenance contributors. Not surprisingly, this is a rather typical situation for many determinations that might have been the best available (and hence preferred) at the time of the CODATA/JANAF/Gurvich evaluations, but have since become overshadowed by newer and more accurate data. Within the ATcT TN, the transition of less accurate determinations toward obsolescence is governed automatically and usually happens gradually: as more accurate determinations are added to the $\mathrm{TN}$, the less accurate determinations-though still contributing to the overall knowledge content of the $\mathrm{TN}$-are slowly eased toward lower provenance ranks.

\subsection{ATcT values for $D_{0}\left(\mathrm{C}_{2}\right)$ and $\Delta_{\mathrm{f}} H^{\circ}\left(\mathrm{C}_{2}\right)$}

CODATA [8] did not evaluate $\mathrm{C}_{2}$, ostensibly because the experimental data available at the time were lacking sufficient accuracy and consistency. JANAF Tables [14, 15] grounded the thermochemistry of this species on the spectroscopically based extrapolation of Messerle and 
Table 1 ATcT values for the $0-\mathrm{K}$ dissociation energies, $D_{0}$, and 298.15 bond dissociation enthalpies, $\mathrm{BDE}_{298}, \mathrm{of}_{2}, \mathrm{C}_{2}, \mathrm{~N}_{2}, \mathrm{O}_{2}, \mathrm{~F}_{2}, \mathrm{HF}, \mathrm{CH}_{\text {, }}$ $\mathrm{CO}, \mathrm{CN}, \mathrm{NO}, \mathrm{OH}, \mathrm{CO}_{2}, \mathrm{H}_{2} \mathrm{O}$, and triplet and singlet $\mathrm{CH}_{2}$ (in $\mathrm{kJ} / \mathrm{mol}$ )

\begin{tabular}{lccc}
\hline Species & $D_{0}$ & BDE $_{298}$ & Uncertainty \\
\hline $\mathrm{H}_{2}$ & $432.068_{06}$ & $435.995_{75}$ & $\pm 0.000_{02}$ \\
$\mathrm{C}_{2}$ & $602.52_{7}$ & $605.03_{1}$ & $\pm 0.27_{8}$ \\
$\mathrm{~N}_{2}$ & 941.146 & 944.870 & \pm 0.047 \\
$\mathrm{O}_{2}$ & $493.687_{8}$ & $498.458_{3}$ & $\pm 0.004_{2}$ \\
$\mathrm{~F}_{2}$ & $154.57_{5}$ & $158.78_{7}$ & $\pm 0.10_{8}$ \\
$\mathrm{HF}$ & 565.966 & 570.082 & \pm 0.008 \\
$\mathrm{CH}$ & $334.60_{2}$ & $338.71_{7}$ & $\pm 0.11_{4}$ \\
$\mathrm{CO}$ & 1072.041 & $1,076.631$ & \pm 0.055 \\
$\mathrm{CN}$ & $745.25_{3}$ & $749.31_{4}$ & $\pm 0.14_{1}$ \\
$\mathrm{NO}$ & 626.830 & 630.574 & \pm 0.060 \\
$\mathrm{OH}$ & 425.625 & 429.735 & \pm 0.026 \\
$\mathrm{CO}_{2}^{\text {b }}$ & 526.150 & 532.182 & \pm 0.025 \\
$\mathrm{H}_{2} \mathrm{O}^{\text {c }}$ & 492.215 & 497.321 & \pm 0.002 \\
$\mathrm{CH}_{2}^{\text {d }}$ (triplet) & $417.90_{0}$ & $422.64_{1}$ & $\pm 0.14_{0}$ \\
$\mathrm{CH}_{2}^{\text {e }}$ (singlet) & $380.23_{3}$ & $385.11_{8}$ & $\pm 0.14_{8}$ \\
\hline
\end{tabular}

The listed values are from ver. 1.118a of the ATcT thermochemical network

a The conversion of $\Delta_{\mathrm{f}} H^{\circ}\left(\mathrm{C}_{2}\right)$ from $0 \mathrm{~K}$ to $298.15 \mathrm{~K}$ uses a newly computed ATcT partition function for $\mathrm{C}_{2}$; with the prior partition function for $\mathrm{C}_{2}$ (from Gurvich et al. [12, 13]), $\mathrm{BDE}_{298}$ value would be $605.43_{0} \mathrm{~kJ} / \mathrm{mol}$

${ }^{b}$ The current total atomization energy of $\mathrm{CO}_{2}$ is $\mathrm{TAE}_{0}\left(\mathrm{CO}_{2}\right)=1,598.191 \pm 0.054 \mathrm{~kJ} / \mathrm{mol}(1,608.812 \mathrm{~kJ} / \mathrm{mol}$ at $298.15 \mathrm{~K})$

c The current total atomization energy of $\mathrm{H}_{2} \mathrm{O}$ is $\mathrm{TAE}_{0}\left(\mathrm{H}_{2} \mathrm{O}\right)=917.840 \pm 0.026 \mathrm{~kJ} / \mathrm{mol}(927.056 \mathrm{~kJ} / \mathrm{mol}$ at $298.15 \mathrm{~K})$

${ }^{d}$ The current total atomization energy of triplet $\mathrm{CH}_{2}$ is $\mathrm{TAE}_{0}\left({ }^{3} \mathrm{CH}_{2}\right)=752.50_{2} \pm 0.12_{7} \mathrm{~kJ} / \mathrm{mol}\left(761.35_{8} \mathrm{~kJ} / \mathrm{mol}\right.$ at $\left.298.15 \mathrm{~K}\right)$

${ }^{\text {e }}$ The current total atomization energy of singlet $\mathrm{CH}_{2}$ is $\mathrm{TAE}_{0}\left({ }^{1} \mathrm{CH}_{2}\right)=714.83_{5} \pm 0.13_{5} \mathrm{~kJ} / \mathrm{mol}\left(723.83_{6} \mathrm{~kJ} / \mathrm{mol}\right.$ at $\left.298.15 \mathrm{~K}\right)$

Kraus [30], taking $D_{0}\left(\mathrm{C}_{2}\right)=589.7 \pm 3.8 \mathrm{~kJ} / \mathrm{mol}^{6}{ }^{6}$ In contrast to this, Huber and Herzberg [31] termed the determination of Messerle and Krauss [30] as 'somewhat doubtful' and listed $D_{0}\left(\mathrm{C}_{2}\right)=599 \mathrm{~kJ} / \mathrm{mol}$ (with an implied uncertainty of about $\pm 9 \mathrm{~kJ} / \mathrm{mol}$ ) based on high-temperature measurements of Brewer et al. [32] and of Kordis and Gingerich [33]. Gurvich et al. [12,13] examined nearly all high-temperature measurements that were available at the time [33-40], and ultimately anchored the thermochemistry of $\mathrm{C}_{2}$ on the same spectroscopic measurement as JANAF, but reinterpreted it as implying $D_{0}\left(\mathrm{C}_{2}\right)=600 \pm 10 \mathrm{~kJ} /$ mol.

The current ATcT value for $D_{0}\left(\mathrm{C}_{2}\right)$ is $602.52_{7} \pm 0.27_{8}$ $\mathrm{kJ} / \mathrm{mol}$ (Table 1). The related $0-\mathrm{K}$ ATcT enthalpy of formation of $\mathrm{C}_{2}$ is $820.26_{3} \pm 0.29_{0} \mathrm{~kJ} / \mathrm{mol}\left(828.72_{9} \mathrm{~kJ} / \mathrm{mol}\right.$ at $298.15 \mathrm{~K}$, Table 2). The Gurvich et al. [12, 13] value

\footnotetext{
${ }^{6}$ Note that there is an inconsistency in the JANAF Tables [14, 15]: the listed enthalpy of formation of $\mathrm{C}_{2}$ was derived in the third edition [14] by combining the assumed bond dissociation energy of $589.7 \pm 3.8 \mathrm{~kJ} / \mathrm{mol}$ with an older value for the enthalpy of formation of $\mathrm{C}$ atom, which is lower by $1.7 \mathrm{~kJ} / \mathrm{mol}$ than the listed value. Thus, from the listed enthalpies of formation for $\mathrm{C}_{2}$ and $\mathrm{C}$, one nominally obtains $D_{0}\left(\mathrm{C}_{2}\right)=593.1 \pm 3.9$, or $3.4 \mathrm{~kJ} / \mathrm{mol}$ higher than their original assumption. The inconsistency stays uncorrected in the fourth edition [15].
}

$\Delta_{\mathrm{f}} H_{0}^{\circ}\left(\mathrm{C}_{2}\right)=822.4 \pm 10 \mathrm{~kJ} / \mathrm{mol}(830.5 \mathrm{~kJ} / \mathrm{mol}$ at $298.15 \mathrm{~K})$ and their $D_{0}\left(\mathrm{C}_{2}\right)=600 \pm 10 \mathrm{~kJ} / \mathrm{mol}$, as well as the nearly identical $D_{0}\left(\mathrm{C}_{2}\right)$ value of Huber and Herzberg [31], are clearly consistent with the ATcT value, though less accurate by one-and-a-half orders of magnitude. The often quoted and used JANAF [14, 15] value $\Delta_{\mathrm{f}} H^{\circ}{ }_{0}\left(\mathrm{C}_{2}\right)=$ $829.3 \pm 3.8 \mathrm{~kJ} / \mathrm{mol}(837.7 \mathrm{~kJ} / \mathrm{mol}$ at $298.15 \mathrm{~K})$ is evidently inconsistent with the current ATcT value. Table 2 also lists the current ATcT enthalpy of formation of carbon atom, $\Delta_{\mathrm{f}} H^{\circ}{ }_{0}(\mathrm{C})=711.395 \pm 0.054 \mathrm{~kJ} / \mathrm{mol}(716.880 \mathrm{~kJ} / \mathrm{mol}$ at $298.15 \mathrm{~K})$. The latter value has changed very slightly since the previously reported [10] interim ATcT value.

The provenance of the ATcT value for $D_{0}\left(\mathrm{C}_{2}\right)$ is quite distributed: $90 \%$ of the provenance contribution is due to 23 determinations, and in order to account for $99.9 \%$ of the provenance, it takes no less than 715 determinations. In spite of the fact that the presence of $\mathrm{C}_{2}$ is clearly visible in nearly every hydrocarbon flame (quoting Hoffmann [41]: 'the lovely blue color of hot hydrocarbon flames is due in large part to emission from excited $\mathrm{C}_{2}$ molecules on their way to soot or $\mathrm{CO}_{2}{ }^{\prime}$ ), and in spite of numerous detailed spectroscopic studies of this molecule [42-51], there is very little in terms of accurate experimental determinations that could help define $D_{0}\left(\mathrm{C}_{2}\right)$. Among the top fifty provenance contributors to the ATcT value, only four are experimental 
Table 2 ATcT enthalpies of formation, $\Delta_{\mathrm{f}} H^{\circ}$, of $\mathrm{H}, \mathrm{C}, \mathrm{N}, \mathrm{O}, \mathrm{F}, \mathrm{C}_{2}$, $\mathrm{HF}, \mathrm{CH}, \mathrm{CO}, \mathrm{CN}, \mathrm{NO}, \mathrm{OH}, \mathrm{CO}_{2}, \mathrm{H}_{2} \mathrm{O}$, and triplet and singlet $\mathrm{CH}_{2}$ at $0 \mathrm{~K}$ and $298.15 \mathrm{~K}$ (in $\mathrm{kJ} / \mathrm{mol}$ )

\begin{tabular}{lccl}
\hline Species & $0 \mathrm{~K}$ & $298.15 \mathrm{~K}$ & Uncertainty \\
\hline $\mathrm{H}$ & $216.034_{03}$ & $217.997_{88}$ & $\pm 0.000_{01}$ \\
$\mathrm{C}$ & 711.395 & 716.880 & \pm 0.054 \\
$\mathrm{~N}$ & 470.573 & 472.435 & \pm 0.023 \\
$\mathrm{O}$ & $246.843_{9}$ & $249.229_{2}$ & $\pm 0.002_{1}$ \\
$\mathrm{~F}$ & 77.287 & 79.393 & \pm 0.053 \\
$\mathrm{C}_{2}$ & $820.26_{3}$ & $828.72_{9}^{\mathrm{a}}$ & $\pm 0.29_{0}$ \\
$\mathrm{HF}$ & -272.644 & -272.691 & \pm 0.053 \\
$\mathrm{CH}$ & $592.82_{7}$ & $596.16_{1}$ & $\pm 0.12_{3}$ \\
$\mathrm{CO}$ & -113.802 & -110.522 & \pm 0.026 \\
$\mathrm{CN}$ & $436.71_{5}$ & $440.00_{1}$ & $\pm 0.14_{5}$ \\
$\mathrm{NO}$ & 90.586 & 91.090 & \pm 0.062 \\
$\mathrm{OH}_{\mathrm{CO}}$ & 37.253 & 37.492 & \pm 0.026 \\
$\mathrm{H}_{2} \mathrm{O}$ & -393.108 & -393.474 & \pm 0.014 \\
$\mathrm{CH}_{2}$ (triplet) & -238.928 & -241.831 & \pm 0.026 \\
$\mathrm{CH}_{2}$ (singlet) & $390.96_{0}$ & $391.51_{8}$ & $\pm 0.13_{4}$ \\
\hline
\end{tabular}

The listed values are from ver. 1.118a of the ATcT thermochemical network

a The conversion of $\Delta_{\mathrm{f}} H^{\circ}\left(\mathrm{C}_{2}\right)$ from $0 \mathrm{~K}$ to $298.15 \mathrm{~K}$ uses a newly computed ATcT partition function for $\mathrm{C}_{2}$; with the prior partition function for $\mathrm{C}_{2}$ (from Gurvich et al. [12,13]), the $298.15 \mathrm{~K}$ value would be $828.330 \mathrm{~kJ} / \mathrm{mol}$

determinations: the Gibbs energy of vaporization of graphite to produce $\mathrm{C}_{2}$ as extracted by a third law treatment of the measurements of Kordis and Gingerich [33], the energy of dissociation of acetylene to $\mathrm{C}_{2}$ and two $\mathrm{H}$ atoms extracted from the measurements of Urdahl et al. [52], the high-temperature equilibrium constant between $\mathrm{C}_{2}$ and $\mathrm{C}$ atoms determined by Wachi and Gilmatrin [38], and a reinterpretation of the bond dissociation measurements by Messerle and Kraus [30] that is very similar to that given by Gurvich et al. [12, 13]. Each of these four experimental determinations individually contributes less than $1 \%$ to the provenance. The other experimental determinations mentioned at the beginning of the $\mathrm{C}_{2}$ discussion are also included in the $\mathrm{TN}$, but they occupy even lower provenance ranks. The primary reasons for a low contribution of experimental determinations to the provenance are their insufficient accuracy and poor mutual consistency. Rather than experiment, the relevant provenance contributors in the current version of ATcT derive from theory: the bond dissociation energy and the energy for loss of two hydrogen atoms from acetylene based on W4.4a calculations of Karton et al. [53-55] and on the FPD method results of Feller et al. [56], together with the analogous quantities based on slightly lower levels of theory, such as W4.3, W4.2, and W4 [53, 55], and on an earlier version of the FPD method [57], as well as the $\mathrm{C}-\mathrm{H}$ bond dissociation energy of $\mathrm{C}_{2} \mathrm{H}$ from an approach that utilized explicitly correlated coupled-cluster methods [6], as well as the same bond energy from a CCSD(T)/CBS-based approach [58].

Although the current ATcT value for $D_{0}\left(C_{2}\right)$ is dominated by virtual (i.e., computational) determinations, rather than actual (i.e., experimental) determinations, this was not necessarily the case in earlier versions of the ATcT TN. The section of $\mathrm{TN}$ relevant to $\mathrm{C}_{2}$ initially contained all the available experimental data mentioned above, but very few high-accuracy computational results. The resulting values for $D_{0}\left(\mathrm{C}_{2}\right)$ and $\Delta_{\mathrm{f}} H^{\circ}\left(\mathrm{C}_{2}\right)$ were rather inaccurate, partly because of the relative paucity of data and partly because of their limited accuracy. In addition, some of the hightemperature determinations had a tendency to skew the resulting bond dissociation energy to higher values, because at that point, the $\mathrm{TN}$ contained a rather limited set of thermochemical cycles involving $\mathrm{C}_{2}$ and thus ATcT had no good thermodynamic pathways to check the involved determinations for consistency. As high-accuracy computational results have gradually appeared and were inserted in the TN, they incrementally boosted the TN knowledge content, allowing ATcT to perform a more rigorous evaluation of the relevant TN section for internal consistency. The resulting $D_{0}\left(\mathrm{C}_{2}\right)$ and $\Delta_{\mathrm{f}} H^{\circ}\left(\mathrm{C}_{2}\right)$ were gradually gaining in accuracy and converging toward the current value, but at the same time, the newer and increasingly accurate theoretical results began pushing the less accurate experiments down the rank list of provenance contributors.

The thermochemistry of $\mathrm{C}_{2}$ is clearly a case where the ATcT results benefit immensely from the availability of high-accuracy state-of-the-art electronic structure methods. However, it is worth stressing here that although the current ATcT thermochemistry of $\mathrm{C}_{2}$ is dominated by theoretical determinations, the results presented here are superior to any of the included computational determinations taken alone. By virtue of the underlying TN approach, the ATcT results reflect a statistically weighted summary consensus of the determinations contributing to their pedigree-after they were brought into mutual consistency by statistically evaluating all available thermochemical cycles-and are thus superior to any of their constituent determinations taken alone.

\subsection{ATcT values for $D_{0}\left(\mathrm{~N}_{2}\right)$ and $\Delta_{\mathrm{f}} H^{\circ}(\mathrm{N})$}

CODATA [8] used a bond dissociation energy of $\mathrm{N}_{2}$ of $941.64 \pm 0.60 \mathrm{~kJ} / \mathrm{mol}$ from Büttenbender and Herzberg [59] to derive the $298.15 \mathrm{~K}$ enthalpy of formation of 
nitrogen atom of $472.68 \pm 0.40 \mathrm{~kJ} / \mathrm{mol}$, which was then adopted by Gurvich et al. [12, 13] and $\operatorname{JANAF}^{7}[14,15]$. In the very early stages of the development of the ATcT TN, when the network was much smaller, the resulting ATcT enthalpy of formation of $\mathrm{N}$ atom was strongly dominated by the same spectroscopic determination by Büttenbender and Herzberg [59]. Consequently, this determination was marked as a 'weak link' in the TN, and steps were undertaken to enhance the TN section surrounding N. More exhaustive literature searches have subsequently unearthed the determinations of Carroll and Mulliken [60] and Roncin et al. [61], and the analyses of Lofthus [62] and Le Roy et al. [63]. However, while their addition to the TN introduced competing values for $D_{0}\left(\mathrm{~N}_{2}\right)$, this enhancement did not create new thermochemical cycles that would allow ATcT to perform more exhaustive checks for consistency in the relevant portion of the TN. A crucial breakthrough toward alleviating the 'weak link' symptom occurred in the form of a tailored collaborative effort with the group of $\mathrm{Ng}$ [64], where accurate synchrotron-based photoionization measurements have been used to determine in three separate ways the onset of photodissociative ionization of $\mathrm{N}_{2}$ (corresponding to the process $\mathrm{N}_{2} \rightarrow \mathrm{N}^{+}+\mathrm{N}+\mathrm{e}^{-}$).

The current ATcT value is $D_{0}\left(\mathrm{~N}_{2}\right)=941.146 \pm$ $0.047 \mathrm{~kJ} / \mathrm{mol}$. In contrast to the very early versions of the TN that suffered from the 'weak link' situation, the provenance of $D_{0}\left(\mathrm{~N}_{2}\right)$ - and hence also the provenance of $\Delta_{\mathrm{f}} H^{\circ}(\mathrm{N})$-is currently quite distributed, with a distribution size not dissimilar to that found for $D_{0}\left(\mathrm{C}_{2}\right)$ : it takes 17 determinations to elucidate $90 \%$ of provenance, and as many as 1,036 determinations to account for $99.9 \%$ of the provenance. However, as opposed to the situation for $\mathrm{C}_{2}$, the primary contributors to the current value of $D_{0}\left(\mathrm{~N}_{2}\right)$ are entirely experimental. The most relevant contributors are the three collaborative photoionization measurements mentioned above [64], the measurements of Roncin et al. [61], the measurement of Carroll and Mulliken [60], as well as the original determination by Büttenbender and Herzberg [59].

The corresponding ATcT value for $\Delta_{\mathrm{f}} H^{\circ}{ }_{0}(\mathrm{~N})=$ $470.573 \pm 0.023 \mathrm{~kJ} / \mathrm{mol}(472.435 \mathrm{~kJ} / \mathrm{mol}$ at $298.15 \mathrm{~K}$, Table 2) coincides with the previously reported [10] interim value. The CODATA [8] value is more than an order of magnitude less accurate and is $0.24 \mathrm{~kJ} / \mathrm{mol}$ higher; perhaps a not entirely unrelated detail is that the bond dissociation energy explicitly quoted by CODATA should have produced an uncertainty for the enthalpy of formation of nitrogen atom of $\pm 0.3_{0} \mathrm{~kJ} / \mathrm{mol}$, but in the final analysis,

\footnotetext{
7 JANAF [14] explicitly declares that it adopts the CODATA value for the enthalpy of formation of $\mathrm{N}$, but lists an uncertainty that is smaller than CODATA's by a factor of 4 , as if the authors failed to convert it from $\mathrm{kcal} / \mathrm{mol}$ to $\mathrm{kJ} / \mathrm{mol}$. The problem is uncorrected in the fourth edition [15].
}

the CODATA Task Group has decided for some reason to increase it to $\pm 0.4_{0} \mathrm{~kJ} / \mathrm{mol}$. One suspects that the undocumented addition of a safety margin to the uncertainty by CODATA is related to the fact that $D_{0}\left(\mathrm{~N}_{2}\right)$ was involved in a very lively controversy during the first half of the twentieth century (see Gaydon's book [65] for a historical overview of this subject).

While the uncertainty of the CODATA value is large enough to accommodate the current ATcT value in the lower section of the bound, the actual CODATA value is outside the ATcT error bar by a substantial margin. ${ }^{8}$ Both the shift in the value and the increased accuracy of the ATcT value are of relevance to high-accuracy theoretical approaches that utilize the total atomization energy route to obtain practical enthalpies of formation, particularly for chemical species that have multiple nitrogen atoms.

\subsection{ATcT values for $D_{0}\left(\mathrm{O}_{2}\right)$ and $\Delta_{\mathrm{f}} H^{\circ}(\mathrm{O})$}

The current ATcT value for $D_{0}\left(\mathrm{O}_{2}\right)=493.687_{8} \pm$ $0.004_{2} \mathrm{~kJ} / \mathrm{mol}$ (Table 1), and the corresponding $\Delta_{\mathrm{f}} H^{\circ}{ }_{0}(\mathrm{O})=$ $246.843_{9} \pm 0.002_{1} \mathrm{~kJ} / \mathrm{mol}\left(249.229_{2} \mathrm{~kJ} / \mathrm{mol}\right.$ at $298.15 \mathrm{~K}$, Table 2); these have not changed from the previous ATcT version [10].

The CODATA [8] value for the enthalpy of formation of oxygen atom is based on $D_{0}\left(\mathrm{O}_{2}\right)=493.58 \pm 0.18 \mathrm{~kJ} / \mathrm{mol}$ obtained by Brix and Herzberg [66], and the resulting $298.15 \mathrm{~K}$ enthalpy of formation for oxygen atom of $249.18 \pm 0.10 \mathrm{~kJ} / \mathrm{mol}$ was adopted by Gurvich et al. [12, 13] and $\operatorname{JANAF}^{5}[14,15]$. The provenance of the ATcT value is reasonably distributed: $90 \%$ of the provenance can be attributed to 4 determinations, and $99.9 \%$ of the provenance to 106 determinations. The prominent contributors are the bond dissociation energy determination of Lewis et al. [67], the ion-pair threshold determination of Martin and Hepburn [68], and the bond dissociation energies determined by Gibson et al. [69] and Cosby and Huestis [70].

Some of the (otherwise very accurate) spectroscopic values for $D_{0}\left(\mathrm{O}_{2}\right)$ that are found in the literature are-in a strict thermodynamic sense-incorrect and require an additional small correction before they can be used for high-accuracy thermochemical purposes. Namely, the thermodynamic definition of dissociation energy is that it corresponds to the energy difference between the lowest existing rovibrational level of a molecule and the lowest existing level of the dissociation asymptote. Both Herzberg [71] and Huber and Herzberg [31] quoted this definition,

\footnotetext{
${ }^{8}$ While a detailed comparison of quantities with vastly different accuracies is nontrivial, particularly if the more accurate value is within the uncertainty bounds of the less accurate value, but the converse is not true, if one anchors the reference frame to the ATcT value for $\Delta_{\mathrm{f}} H^{\circ}(\mathrm{N})$, the corresponding CODATA [8] value is too high by more than 20 standard deviations.
} 
and yet the dissociation energy of Brix and Herzberg [66] was given with respect to the nonexistent $v=0$, $N=J=0$ level of the $X^{3} \Sigma_{g}^{-}$state. Prima facie, the lowest existing level in the ground state of $\mathrm{O}_{2}$ would be $1.783 \mathrm{~cm}^{-1}$ lower and would correspond to $N=0, J=1$ $\left(\mathrm{F}_{1}\right)$, but that level is wiped out by nuclear spin statistics in the dominant isotopic variant ${ }^{16} \mathrm{O}_{2}$. The lowest actual level in $X^{3} \Sigma_{g}^{-}$of ${ }^{16} \mathrm{O}_{2}$ is $N=1, J=0\left(\mathrm{~F}_{3}\right)$, which is $1.086 \mathrm{~cm}^{-1}$ lower than the nonexistent reference level. CODATA [8] apparently entirely ignored this (admittedly small) correction to the Brix and Herzberg $D_{0}\left(\mathrm{O}_{2}\right)$ value [66], presumably considering it superfluous in view of the $\pm 15 \mathrm{~cm}^{-1}$ overall uncertainty of that determination. However, Gibson et al. [69] and Lewis and al. [67] follow suit and also refer their $D_{0}$ to the same nonexistent level; in their case, the correction is relevant since they both quote sub-cm ${ }^{-1}$ uncertainties. In a similar vein, Martin and Hepburn [68] explicitly report their ion-pair formation threshold relative to the $N=1, J=2$ level of the ground state of $\mathrm{O}_{2}$, which is $2.1 \mathrm{~cm}^{-1}$ above the lowest existing level of $X^{3} \Sigma_{g}^{-}$of $\mathrm{O}_{2}$-again a relevant correction in view of their uncertainty of $\pm 0.7 \mathrm{~cm}^{-1}$.

The ATcT value for $\Delta_{\mathrm{f}} H^{\circ}(\mathrm{O})$ is significantly more accurate than the value selected by CODATA [8] (by more than two orders of magnitude) and slightly higher (by $0.05 \mathrm{~kJ} / \mathrm{mol}$ ). As in the case of $\mathrm{N}$ atom, the current value for the $\mathrm{O}$ atom is of relevance to high-accuracy theoretical approaches that utilize the total atomization energy route to obtain enthalpies of formation.

\subsection{ATcT values for $D_{0}\left(\mathrm{~F}_{2}\right)$ and $\Delta_{\mathrm{f}} H^{\circ}(\mathrm{F})$}

The current ATcT value for $D_{0}\left(\mathrm{~F}_{2}\right)=154.57_{5} \pm 0.10_{8} \mathrm{~kJ} /$ mol (Table 1), or, equivalently, $\Delta_{\mathrm{f}} H^{\circ}{ }_{0}(\mathrm{~F})=77.287 \pm$ $0.053 \mathrm{~kJ} / \mathrm{mol}(79.393 \mathrm{~kJ} / \mathrm{mol}$ at $298.15 \mathrm{~K}$, Table 2$)$. The ATcT value for the enthalpy of formation of $\mathrm{F}$ atom is nearly six times more accurate, but otherwise numerically very similar to the CODATA [8] value of $\Delta_{\mathrm{f}} H^{\circ}{ }_{298}(\mathrm{~F})=$ $79.38 \pm 0.30 \mathrm{~kJ} / \mathrm{mol}$.

The CODATA value for $\Delta_{\mathrm{f}} H^{\circ}(\mathrm{F})$ was obtained by adopting $D_{0}\left(\mathrm{~F}_{2}\right)=154.56 \pm 0.60 \mathrm{~kJ} / \mathrm{mol}$ from Colbourn et al. [72]. The latter determination requires additional discussion. Though often referred to as a spectroscopic measurement, it is, in fact, an educated estimate based on spectroscopic observations on $\mathrm{F}_{2}$, rather than a direct measurement of $D_{0}\left(\mathrm{~F}_{2}\right)$. Colbourn et al. have spectroscopically determined the $B_{v}$ and $G_{v}$ values from $v=0$ to $v=22$ of the $X^{1} \Sigma_{g}^{+}$state of $\mathrm{F}_{2}$. They concluded that the dissociation limit must be higher than the highest observed vibrational level. The inference that the $v=22$ vibrational level must be bound was rationalized by noting that the ground state curve is unlikely to have a barrier on the basis that both the $\mathrm{C}_{6} r^{-6}$ and the $\mathrm{C}_{8} r^{-8}$ terms in the long-range potential correspond to attraction between the atoms and thus have the same sign. Colbourn et al. further remarked that an extrapolation of the vibrational levels beyond $v=22$ to the dissociation limit would be difficult because the intervals between the high vibrational levels vary rapidly and follow no obvious pattern (a situation not dissimilar to the case of $D_{0}(\mathrm{OH})[73,74]$, now apparently considered to be a classic [75]). Colbourn et al. [72] estimate that the dissociation limit of $\mathrm{F}_{2}$ is $90 \mathrm{~cm}^{-1}$ higher than the $v=22$ vibrational level, with an uncertainty of $\pm 50 \mathrm{~cm}^{-1}$, or slightly more than half of the incremental interval. The exact procedure by which Colbourn et al. arrived at this estimate is not given in their paper, but one suspects that the expertise of this world-renowned spectroscopic group must have played an important role during the process.

Several years ago, Bytautas and Ruedenberg [76] carefully analyzed the long-range region of the ground state potential energy function of $\mathrm{F}_{2}$ (obtained by their CEEIS method). They found that while the London dispersion interaction, which scales as $r^{-6}$, is attractive, the interaction between quadrupoles of the fluorine atoms, which scales as $r^{-5}$, is repulsive because of coaxial alignment. There is also an additional repulsive force due to loss of spin-orbit coupling upon the bond formation. Consequently, their potential energy curve has a small $\left(\sim 9 \mathrm{~cm}^{-1}\right)$ dissociation barrier at about $4 \AA$ A. The quandary that has arisen immediately after the work of Bytautas and Ruedenberg was published, concerns the issue of whether the $9 \mathrm{~cm}^{-1}$ barrier affects the $D_{0}$ estimate of Colbourn et al. [72] or not. Clearly, the barrier is much too small to vitiate the main stepping stone in the estimate of Colbourn et al. [72], which is the assumption that the highest observed vibrational level, $90 \mathrm{~cm}^{-1}$ below the presumed dissociation limit, is fully bound. Would the knowledge of the barrier have resulted in an estimate of $D_{0}$ that was lower by $9 \mathrm{~cm}^{-1}$, or would it have perhaps resulted in an estimated error bar larger than $\pm 50 \mathrm{~cm}^{-1}$ ? It is unclear that it would cause either of the two, particularly since the estimate of Colbourn et al. explicitly did not rely on a straightforward extrapolation of the observed vibrational levels, and likely relied heavily on spectroscopic experience.

An additional and more serious problem surrounding the correct value of $D_{0}\left(\mathrm{~F}_{2}\right)$ has arisen even before the discovery of the dissociation barrier by Bytautas and Ruedenberg [76]. Yang et al. [77] have reported the ion-pair formation threshold of $\mathrm{F}_{2}$ (corresponding to the process $\mathrm{F}_{2} \rightarrow \mathrm{F}^{+}+\mathrm{F}^{-}$), which was obtained by velocity mapping the $\mathrm{F}^{-}$fragment. When combined with the generally accepted values for the ionization energy and electron affinity of $\mathrm{F}$ atom, it produced $D_{0}\left(\mathrm{~F}_{2}\right)=154.96 \pm 0.10 \mathrm{~kJ} /$ $\mathrm{mol}$; this value was subsequently slightly lowered in an erratum [78] to $154.92 \mathrm{~kJ} / \mathrm{mol}$. The value of Yang et al. appears six times more accurate than the estimate of Colbourn et al. but is $0.36 \mathrm{~kJ} / \mathrm{mol}$ higher. 
From the perspective of traditional sequential thermochemistry, establishing whether the Colbourn et al. estimate (either uncorrected or lowered by $0.11 \mathrm{~kJ} / \mathrm{mol}$ on account of the dissociation barrier) or the higher determination of Yang et al. is correct is a crucial issue: once one of the conflicting determinations is selected as the preferred value, it immediately implies a particular value for $\Delta_{\mathrm{f}} H^{\circ}(\mathrm{F})$.

However, from the perspective of the ATcT approach, establishing beforehand which of the possibilities is correct is not a crucial issue at all. Arbitrating between mutually inconsistent determinations is one of the things that the ATcT approach is explicitly designed to do: as long as there are sufficient alternate thermochemical cycles in the $\mathrm{TN}$, errant determination(s) will be identified during the ATcT analysis and brought into consistency with the rest of the TN by augmenting their uncertainties. As we shall show in a moment, the $\mathrm{TN}$ contains a truly large number of determinations that can help establish the dissociation energy of $\mathrm{F}_{2}$ both directly and through alternate thermochemical cycles, and thus ATcT should have no problem with such arbitration.

In general, the ATcT analysis typically finds that the optimal solutions are outside the initially assigned uncertainties for roughly $10 \%$ of the determinations (or about double the expected number if all initial uncertainties truly corresponded to probabilistically correct $95 \%$ confidence intervals). Since the introduction of the ion-pair threshold of Yang et al. [77, 78] into the TN a number of versions ago (using their original uncertainty of $\pm 8 \mathrm{~cm}^{-1}$ or $\pm 0.09_{6} \mathrm{~kJ} / \mathrm{mol}$ ), the ATcT analysis consistently finds this determination to be problematic, unless the original uncertainty is increased by approximately a factor of 3.6, to $\pm 0.34_{4} \mathrm{~kJ} / \mathrm{mol}$. Other than it being inconsistent with the remaining knowledge content of the $\mathrm{TN}$ (where the latter consists of the cumulative knowledge of well over a thousand related determinations, vide infra), it is unclear at this point what exactly may be the problem with the threshold of Yang et al. or with its original uncertainty.

As hinted to earlier, the provenance of the ATcT value for $D_{0}\left(\mathrm{~F}_{2}\right)$ is extremely distributed-even more so than the other species examined in this report: the top $90 \%$ provenance is spread out over 78 determinations, while accounting for $99.9 \%$ of the provenance involves 1,197 determinations! The prominent contributors to the provenance are a mix of experiment and theory. They include the experimental ionpair formation threshold by Yang et al. [77, 78] (with an uncertainty augmented during the ATcT analysis), the bond dissociation determination of Colbourn et al. [72], together with the theoretical bond dissociation energies of Bytautas et al. [79], Csontos et al. [80], Harding et al. [4], Karton et al. [5], Feller et al. [56], as well as a large number of other experimental and theoretical determinations. These include additional species such as $\mathrm{ClF}, \mathrm{CF}_{4}, \mathrm{Cl}, \mathrm{FOF}, \mathrm{HF}, \mathrm{HCl}, \mathrm{CF}$, $\mathrm{CF}_{2}, \mathrm{CF}_{3}, \mathrm{COF}_{2}, \mathrm{C}_{2} \mathrm{~F}_{4}, \mathrm{CO}_{2}, \mathrm{CH}_{4}, \mathrm{CH}, \mathrm{H}_{2} \mathrm{O}, \mathrm{H}_{2}$, and graphite, through alternative thermochemical cycles that ATcT find to be of some relevance to establishing the final result. At first blush, some of these additional species involved in the provenance may appear surprising, though they can be all rationalized. For example - to provide just a few random examples - the enthalpy of reaction of $F_{2}$ with $\mathrm{Cl}$ atoms to produce $\mathrm{ClF}$ and $\mathrm{F}$ atoms corresponds to the difference in the bond dissociation energies of $\mathrm{ClF}$ and $\mathrm{F}_{2}$. When combined with the equilibrium constant for the reaction of $\mathrm{F}_{2}$ and $\mathrm{Cl}_{2}$ to produce $\mathrm{ClF}$, it corresponds to the difference in the bond dissociation energies of $\mathrm{Cl}_{2}$ and $\mathrm{F}_{2}$. Or, the calorimetric combustion of graphite in $\mathrm{F}_{2}$ to produce $\mathrm{CF}_{4}$, when combined with the vaporization enthalpy of graphite and either with the successive bond dissociation energies of $\mathrm{CF}_{4}$ or with the total atomization energy of $\mathrm{CF}_{4}$, produces a net cycle corresponding to two $\mathrm{F}_{2}$ molecules dissociating to constituent atoms. Taken alone-such as would be the case in sequential thermochemistry-none of these alternate thermochemical cycles would be able to sufficiently accurately establish the bond dissociation energy of $\mathrm{F}_{2}$. However, within the ATcT TN approach, which attempts to satisfy all available thermochemical cycles simultaneously, the additional thermochemical cycles synergistically enhance the overall knowledge about a satisfactory value for $D_{0}\left(\mathrm{~F}_{2}\right)$ in a way that becomes relevant to the final result.

As mentioned at the beginning of the subsection on $\mathrm{F}_{2}$, while the ATcT value and the CODATA value for the enthalpy of formation of $\mathrm{F}$ atom differ in their accuracy, their nominal values are numerically nearly identical-a fortuitous coincidence in view of the fact that the ATcT value is highly independent from the $D_{0}\left(\mathrm{~F}_{2}\right)$ value of Colbourn et al. [72]; the latter determination contributes only about $3 \%$ to the provenance of the ATcT value. From the ATcT value for $D_{0}\left(\mathrm{~F}_{2}\right)$, one can infer that the dissociation limit is located $91 \pm 9 \mathrm{~cm}^{-1}$ beyond the last vibrational level observed by Colbourn et al. Their estimate was $90 \pm 50 \mathrm{~cm}^{-1}$. The two values are fortuitously in nearperfect agreement, much better than statistically justified by the two uncertainties.

Csontos et al. [80] have quite recently confirmed the existence of the dissociation barrier of Bytautas and Ruedenberg [76] by using several multi-reference methods, and have computed $D_{0}\left(\mathrm{~F}_{2}\right)=154.95 \pm 0.48 \mathrm{~kJ} / \mathrm{mol}$ using an enhanced HEAT-like approach. Csontos et al. [80] noted that the value of Yang et al. [78] of $D_{0}\left(\mathrm{~F}_{2}\right)=154.92 \pm$ $0.10 \mathrm{~kJ} / \mathrm{mol}$ and the value of $D_{0}\left(\mathrm{~F}_{2}\right)=154.52 \pm 0.12 \mathrm{~kJ} /$ mol based on a previously reported [10] interim ATcT value for $\Delta_{\mathrm{f}} H^{\circ}{ }_{0}(\mathrm{~F})=77.26 \pm 0.06 \mathrm{~kJ} / \mathrm{mol}$ are outside each other's error bars, but the uncertainty of their computed bond 
dissociation energy, although remarkably low, was not low enough for them to be able to make a distinction between the two values. However, they remarked that their computed value 'almost precisely agrees' with the value of Yang et al. [78], and indicated support for the latter. Csontos et al. [80] emphasized the fact that neither the experimental ion-pair threshold nor the computed value would suffer from the existence of the dissociation barrier in the ground state of $\mathrm{F}_{2}$, while direct experimental measurements of the dissociation energy which would. Finally, they conclude that "the ATcT approach uses $D_{0}\left(\mathrm{~F}_{2}\right)$ reported by Colbourn and co-workers, which is derived from extrapolation of the vibrational levels for the ground state $\mathrm{F}_{2}$ molecule to the dissociation limit" and that because of the neglect of the dissociation barrier "the uncertainties [of the ATcT values for $D_{0}\left(\mathrm{~F}_{2}\right)$ and $\left.\Delta_{\mathrm{f}} H^{\circ}(\mathrm{F})\right] \ldots$ should be increased." The quoted conclusions of Csontos et al. [80] are incorrect; these authors assumed that the ATcT result is derived directly from the value of Colbourn et al. [72], while in fact, as we have shown above, the provenance of the ATcT values for $D_{0}\left(\mathrm{~F}_{2}\right)$ and $\Delta_{\mathrm{f}} H^{\circ}(\mathrm{F})$ is highly distributed and essentially (in fact, $97 \%$ ) independent of the value of Colbourn et al. As discussed above, the numerical near-coincidence between the estimate of Colbourn et al. and the roughly five times more accurate ATcT value is fortuitous. Furthermore, the possible influence of the dissociation barrier on the ATcT result was checked immediately after the result of Bytautas and Ruedenberg [79] became public. With the possible exception of the estimate of Colbourn et al. [72], none of the other $\sim 1,200$ determinations contributing to the provenance of the thermochemistry of $\mathrm{F}$ is affected by the dissociation barrier in the ground state of $\mathrm{F}_{2}$. Furthermore, irrespective of whether the estimate of Colbourn et al. requires an adjustment or not, its contribution to the final ATcT result is quite small, and a small change in that value would negligibly affect the ATcT value and/or its uncertainty.

\subsection{Current ATcT values for $D_{0}(\mathrm{HF}), D_{0}(\mathrm{CH}), D_{0}(\mathrm{CO})$, $D_{0}(\mathrm{CN}), D_{0}(\mathrm{NO}), D_{0}(\mathrm{OH}), D_{0}\left(\mathrm{CO}_{2}\right), D_{0}\left(\mathrm{H}_{2} \mathrm{O}\right)$, and $D_{0}\left(\mathrm{CH}_{2}\right)$}

The ATcT bond dissociation energies of $\mathrm{HF}, \mathrm{CH}, \mathrm{CO}$, $\mathrm{CN}, \mathrm{NO}, \mathrm{OH}, \mathrm{CO}_{2}, \mathrm{H}_{2} \mathrm{O}$, and triplet and singlet $\mathrm{CH}_{2}$ are given in Table 1 , and the corresponding enthalpies of formation are listed in Table 2. The essential ATcT thermochemistry for $\mathrm{H}_{2} \mathrm{O}$ has been published recently [11]. Strictly speaking, the ATcT results for the other species represent interim values, since the corresponding sections of the TN have not yet been finalized and analyzed in earnest. However, it would be quite surprising if these interim values underwent a substantial change during the final analysis.

\subsection{Benchmarking the benchmarks}

The $D_{0}$ values given in Table 1 are used in the companion paper [7] for benchmarking highly accurate computational results obtained by the FPD procedure. These theoretical results are benchmarks in their own right: the underlying computations have been carried out at the highest level currently feasible by the available hardware, and the individual sources of error were carefully monitored and minimized during each of the computational steps. It goes without saying that in order to keep the benchmarking procedure as objective and independent as possible, the FPD computational results from the companion paper have not been included in the current TN. The agreement between the ATcT results and the computed $D_{0}$ values is very good indeed: in all cases, the two sets display an abundant overlap within their uncertainties, except for $\mathrm{C}_{2}$, where the overlap is rather marginal. The latter, however, does not come as a great surprise: the ATcT result for $\mathrm{C}_{2}$ suffers from a paucity of good experimental data as well as from the fact that the corresponding TN section is somewhat underdeveloped in terms of available thermochemical cycles, and, at the same time, the computational efforts are rendered complex by the multi-configurational character of $\mathrm{C}_{2}$.

From the viewpoint of ATcT, benchmarking state-ofthe-art theory is a two-way street. Once the fidelity level of the benchmarked theoretical results is understood, agreement between the computed results and the ATcT values indirectly also validates the latter. Conversely, if disagreement is found for a particular chemical species, it signals a problem either with the computation or with the TN section related to the species in question, or perhaps both. Furthermore, upon conclusion of the benchmarking procedure, the ATcT TN is ready to incorporate the just benchmarked theoretical results, as well as additional computations that use the newly benchmarked theoretical approach and target the introduction of new chemical species into the $\mathrm{TN}$ or fortification of underdeveloped sections of the TN.

\section{Conclusions}

The current ATcT results for the bond dissociation energies of the homonuclear diatomics $\mathrm{H}_{2}, \mathrm{C}_{2}, \mathrm{~N}_{2}, \mathrm{O}_{2}$, and $\mathrm{F}_{2}$ are reported and compared to values found in traditional thermochemical tabulations. The provenance of the ATcT values, obtained by examining the results of the variance decomposition approach, is discussed. The results that are presented here illustrate, inter alia, that the underlying TN approach produces values that generally have a significantly distributed provenance and thus, as opposed to values obtained by traditional sequential thermochemistry, 
do not critically depend on the reliability of a single measurement. In addition, the bond dissociation energy of $\mathrm{N}_{2}$ illustrates a case that involves the resolution of a 'weak link' in the TN by acquiring additional experimental data. The bond dissociation energy of $\mathrm{O}_{2}$ illustrates a case where the reported measurements are very accurate, but need additional corrections in order to conform to the thermochemical definition of a bond dissociation energy. The thermochemistry of $\mathrm{C}_{2}$ illustrates a case where ATcT rely on state-of-the-art electronic structure methods because of a paucity of sufficiently accurate and mutually consistent experimental measurements, while the bond dissociation energy of $F_{2}$ illustrates a case where ATcT use the cumulative knowledge content of the TN to identify and resolve an inconsistent piece of information. Ramifications in terms of enthalpies of formation of atoms, which are fundamental thermochemical quantities, are also discussed. The current ATcT bond dissociation energies and enthalpies of formation of $\mathrm{HF}, \mathrm{CH}, \mathrm{CO}, \mathrm{CN}, \mathrm{NO}, \mathrm{OH}, \mathrm{CO}_{2}, \mathrm{H}_{2} \mathrm{O}$, and triplet and singlet $\mathrm{CH}_{2}$ are also given.

Acknowledgments This work was supported by the US Department of Energy, Office of Science, Office of Basic Energy Sciences, Division of Chemical Sciences, Geosciences and Biosciences under Contract No. DE-AC02-06CH11357.

Open Access This article is distributed under the terms of the Creative Commons Attribution License which permits any use, distribution, and reproduction in any medium, provided the original author(s) and the source are credited.

\section{References}

1. Ruscic B, Pinzon RE, Morton ML, von Laszewski G, Bittner SJ, Nijsure SG, Amin KA, Minkoff M, Wagner AF (2004) Introduction to Active Thermochemical Tables: several "key" enthalpies of formation revisited. J Phys Chem A 108:9979-9997

2. Ruscic B, Pinzon RE, von Laszewski G, Kodeboyina D, Burcat A, Leahy D, Montoya D, Wagner AF (2005) Active Thermochemical Tables: thermochemistry for the 21 st century. J Phys: Conf Ser 16:561-570

3. Klopper W, Ruscic B, Tew DP, Bischoff FA, Wolfsegger S (2009) Atomization energies from coupled-cluster calculations augmented with explicitly-correlated perturbation theory. Chem Phys 356:14-24

4. Harding ME, Vázquez J, Ruscic B, Wilson AK, Gauss J, Stanton JF (2008) HEAT: high accuracy extrapolated ab initio thermochemistry. III. Additional improvements and overview. J Chem Phys 128:114111

5. Karton A, Rabinovich E, Martin JML, Ruscic B (2006) W4 theory for computational thermochemistry: in pursuit of confident sub-kJ/mol predictions. J Chem Phys 125:144108

6. Aguilera-Iparraguirre J, Boese AD, Klopper W, Ruscic B (2008) Accurate ab initio computation of thermochemical data for $\mathrm{C}_{3} \mathrm{H}_{\mathrm{x}}$ $(\mathrm{x}=0, \ldots, 4)$ species. Chem Phys 346:56-68

7. Feller D, Peterson KA, Ruscic B (2013) Improved accuracy benchmarks of small molecules using correlation consistent basis sets. Theor Chem Acc. doi:10.1007/s00214-013-1407-z
8. Cox JD, Wagman DD, Medvedev VA (1989) CODATA key values for thermodynamics. Hemisphere, New York

9. Ruscic B, Pinzon RE, Morton ML, Srinivasan NK, Su M-C, Sutherland JW, Michael JV (2006) Active Thermochemical Tables: accurate enthalpy of formation of hydroperoxyl radical, $\mathrm{HO}_{2}$. J Phys Chem A 110:6592-6601

10. Stevens WR, Ruscic B, Baer T (2010) The heats of formation of $\mathrm{C}_{6} \mathrm{H}_{5}, \mathrm{C}_{6} \mathrm{H}_{5}{ }^{+}$, and $\mathrm{C}_{6} \mathrm{H}_{5} \mathrm{NO}$ by TPEPICO and Active Thermochemical Tables analysis. J Phys Chem A 114:13134-13145

11. Ruscic B (2013) Active Thermochemical Tables: water and water dimer. J Phys Chem A. doi:10.1021/jp403197t

12. Gurvich LV, Veyts IV, Alcock CB (1989) Thermodynamic properties of individual substances, 4th edn, vol 1, parts 1 and 2 . Hemisphere, New York

13. Gurvich LV, Veyts IV, Alcock CB (1991) Thermodynamic Properties of Individual Substances, 4th edn, vol 2, parts 1 and 2. Hemisphere, New York

14. Chase MW, Davies CA, Downey Jr JR, Frurip DJ, McDonald RA, Syverud AN (1985) JANAF thermochemical tables, vol 14, 3rd edn. J Phys Chem Ref Data (Suppl 1)

15. Chase Jr MW (ed) (1998) NIST-JANAF Thermochemical Tables, 4th edn. J Phys Chem Ref Data, Monograph 9

16. Herzberg G (1970) The dissociation energy of the hydrogen molecule. J Mol Spectrosc 33:147-168

17. Liu J, Salumbides EJ, Hollenstein U, Koelemeij JCJ, Eikema KSE, Ubachs W, Merkt F (2009) Determination of the ionization and dissociation energies of the hydrogen molecule. J Chem Phys 130:174306

18. Mohr PJ, Taylor BN, Newell DB (2008) CODATA recommended values of the fundamental physical constants: 2006. J Phys Chem Ref Data 37:1187-1284

19. Erickson GW (1977) Energy levels of one-electron atoms. J Phys Chem Ref Data 6:831-869

20. Zhang YP, Cheng CH, Kim JT, Stanojevic J, Eyler EE (2004) Dissociation energies of molecular hydrogen and the hydrogen molecular ion. Phys Rev Lett 92:203003

21. Stoicheff BP (2001) On the dissociation energy of molecular hydrogen. Can J Phys 79:165-172

22. Jennings DE, Bragg SL, Brault JW (1984) The $v=0-0$ spectrum of $\mathrm{H}_{2}$. Astrophys J 282:L85-L88

23. de Lange A, Reinhold E, Ubachs W (2002) Spectroscopy on some $\mathrm{g}$ symmetry states in $\mathrm{H}_{2}$ and determination of the ionization potential. Phys Rev A 65:064501

24. Piszczatowski K, Lach G, Przybytek M, Komasa J, Pachucki K, Jeziorski B (2009) Theoretical determination of the dissociation energy of molecular hydrogen. J Chem Theory Comput 5:3039-3048

25. Johnson WR, Soff G (1985) The Lamb shift in hydrogen-like atoms, $1<=\mathrm{Z}<=110$. Atomic Data Nucl Data Tables 33:405446

26. Moss RE (1993) Calculations for the vibration-rotation levels of $\mathrm{H}_{2}{ }^{+}$in its ground and first excited electronic states. Mol Phys 80:1541-1554

27. Schwartz C, Le Roy RJ (1987) Nonadiabatic eigenvalues and adiabatic matrix elements for all isotopes of diatomic hydrogen. J Mol Spectrosc 121:420-439

28. Wolniewicz L (1995) Nonadiabatic energies of the ground state of the hydrogen molecule. J Chem Phys 103:1792-1799

29. Kolos W, Rychlewski J (1993) Improved theoretical dissociation energy and ionization potential for the ground state of the hydrogen molecule. J Chem Phys 98:3960-3967

30. Messerle G, Krauss LZ (1967) Die Dissoziation des $C_{2}$-Moleküls durch Rotation. Z Naturforsch A 22:2023-2026a

31. Huber KP, Herzberg G (1979) Molecular spectra and molecular structure. IV. Constants of diatomic molecules. Van Nostrand Reinhold, New York 
32. Brewer L, Hicks WR, Krikorian OH (1962) Heat of sublimation and dissociation energy of gaseous $\mathrm{C}_{2}$. J Chem Phys 36:182-188

33. Kordis J, Gingerich KA (1973) Gaseous phosphorus compounds. IX. Mass spectrometric studies of equilibria in the carbon-phosphorus system. J Chem Phys 58:5058-5066

34. Chupka WA, Inghram MG (1955) Direct determination of the heat of sublimation of carbon with the mass spectrometer. J Phys Chem 59:100-104

35. Drowart J, Bums RP, DeMaria G, Inghram MG (1959) Mass spectrometric study of carbon vapor. J Chem Phys 31:1131-1132

36. Burns RP, Jason AJ (1964) Evaporation coefficient of graphite. J Chem Phys 40:1161

37. Zavitsanos PD (1970) The vaporisation of pyrolytic graphite. In: Price P, Williams JE (eds) 2nd European symposium on the timeof-flight mass spectrometer, dynamics mass spectrometry series. Heyden, London

38. Wachi FM, Gilmartin DE (1972) Heat of formation and entropy of $\mathrm{C}_{3}$ molecule. High Temp Sci 4:423-431

39. Wyatt JR, Stafford FE (1972) Mass spectrometric determination of the heat of formation of ethynyl radical, $\mathrm{C}_{2} \mathrm{H}$, and some related species. J Phys Chem 76:1913-1918

40. Zavitsanos PD, Carlson GA (1973) Experimental study of the sublimation of graphite at high temperatures. J Chem Phys 59:2966-2973

41. Shaik S, Rzepa HS, Hoffmann R (2013) One molecule, two atoms, three views, four bonds? Angew Chem Int Ed 52: 3020-3033

42. Brooke JSA, Bernath PF, Schmidt TW, Bacskay GB (2013) Line strengths and updated molecular constants for the C2 Swan system. J Quant Spectrosc Rad Trans 124:11-20

43. Bornhauser P, Sych Y, Knopp G, Gerber T, Radi PP (2011) Shedding light on a dark state: the energetically lowest quintet state of $\mathrm{C}_{2}$. J Chem Phys 134:044302

44. Nakajima M, Joester JA, Page NI, Reilly NJ, Bacskay GB, Schmidt TW, Kable SH (2009) Quantum chemical study and experimental observation of a new band system of $\mathrm{C}_{2}, \mathrm{e}^{3} \Pi_{\mathrm{g}}-\mathrm{c}$ ${ }^{3} \Sigma_{\mathrm{u}}^{+}$. J Chem Phys 131:044301

45. Tanabashi A, Hirao T, Amano T, Bernath PF (2007) The Swan system of $\mathrm{C}_{2}$ : a global analysis of Fourier transform emission spectra. Astrophys J Suppl Ser 169:472-484

46. Kokkin DL, Bacskay GB, Schmidt TW (2007) Oscillator strengths and radiative lifetimes for $\mathrm{C}_{2}$ : Swan, Ballik-Ramsay, Phillips, and $\mathrm{d}^{3} \Pi_{\mathrm{g}}-\mathrm{c}{ }^{3} \Sigma_{\mathrm{u}}^{+}$systems. J Chem Phys 126:084302

47. Joester JA, Nakajima M, Reilly NJ, Kokkin DL, Nauta K, Kable SH, Schmidt TW (2007) The $\mathrm{d}^{3} \Pi_{\mathrm{g}}-\mathrm{c}{ }^{3} \Sigma_{\mathrm{u}}^{+}$band system of $\mathrm{C}_{2}$. J Chem Phys 127:214303

48. Wakabayashi T, Ong A-L, Krätschmer W (2002) Laser induced fluorescence spectra of the D ${ }^{1} \Sigma_{\mathrm{u}}^{+}-\mathrm{B}{ }^{1}{ }^{1} \Sigma_{\mathrm{g}}^{+}$and $\mathrm{C}{ }^{1} \Pi_{\mathrm{g}}-\mathrm{A}{ }^{1} \Pi_{\mathrm{u}}$ systems in solid Ne. J Chem Phys 116:5996-6001

49. Lloyd GM, Ewart P (1999) High resolution spectroscopy and spectral simulation of $\mathrm{C}_{2}$ using degenerate four-wave mixing. J Chem Phys 110:385-392

50. Prasad CVV, Bernath PF (1994) Fourier transform spectroscopy of the Swan $\left(\mathrm{d}^{3} \Pi_{\mathrm{g}}-\mathrm{a}{ }^{3} \Pi_{\mathrm{u}}\right)$ system of the jet-cooled $\mathrm{C}_{2}$ molecule. Astrophys J 426:812-821

51. Martin M (1992) $C_{2}$ spectroscopy and kinetics. J Photochem Photobiol, A 66:263-289

52. Urdahl RS, Bao Y, Jackson WM (1991) An experimental determination of the heat of formation of $\mathrm{C}_{2}$ and the $\mathrm{C}-\mathrm{H}$ bond dissociation energy in $\mathrm{C}_{2} \mathrm{H}$. Chem Phys Lett 178:425-428

53. Karton A, Taylor PR, Martin JML (2007) Basis set convergence of post-CCSD contributions to molecular atomization energies. J Chem Phys 127:064104

54. Karton A, Tarnopolsky A, Lamere J-F, Schatz GC, Martin JML (2008) Highly accurate first-principles benchmark data sets for the parametrization and validation of density functional and other approximate methods. Derivation of a robust, generally applicable, double-hybrid functional for thermochemistry and thermochemical kinetics. J Phys Chem A 112:12868-12886

55. Karton A, Tarnopolsky A, Martin JML (2009) Atomization energies of the carbon clusters $C_{n}(n=2-10)$ revisited by means of W4 theory as well as density functional, Gn, and CBS methods. Mol Phys 107:977-990

56. Feller D, Peterson KA, Dixon DA (2008) A survey of factors contributing to accurate theoretical predictions of atomization energies and molecular structures. J Chem Phys 129:204105

57. Feller D, Peterson KA (2007) Probing the limits of accuracy in electronic structure calculations: is theory capable of results uniformly better than "chemical accuracy"? J Chem Phys 126:114105

58. Peterson KA, Dunning TH Jr (1997) Benchmark calculations with correlated molecular wave functions. VIII. Bond energies and equilibrium geometries of the $\mathrm{CH}_{n}$ and $\mathrm{C}_{2} \mathrm{H}_{n}(\mathrm{n}=1-4)$ series. J Chem Phys 106:4119-4140

59. Büttenbender G, Herzberg G (1935) Über die Struktur der zweiten positiven Stickstoffgruppe und die Prädisssoziation des $\mathrm{N}_{2^{-}}$ Moleküls. Ann Phys 413:577-610

60. Carroll PK, Mulliken RS (1965) ${ }^{3} \Pi$ levels and predissociations of $\mathrm{N}_{2}$ near the $12.135 \mathrm{eV}$ dissociation limit. J Chem Phys 43:2170-2179

61. Roncin J-Y, Launay F, Larzilliere M (1984) Evidence for predissociation of $\mathrm{N}_{2}$ into $\mathrm{N}\left({ }^{2} \mathrm{D}\right)+\mathrm{N}\left({ }^{2} \mathrm{D}\right)$ from new high-resolution vacuum-ultraviolet emission bands. Phys Rev Lett 53:159-162

62. Lofthus A, Krupenie PH (1977) The spectrum of molecular nitrogen. J Phys Chem Ref Data 6:113-307

63. Le Roy RJ, Huang Y, Jary C (2006) An accurate analytic potential function for ground-state $\mathrm{N}_{2}$ from a direct-potential-fit analysis of spectroscopic data. J Chem Phys 125:164310

64. Tang X, Hou Y, Ng CY, Ruscic B (2005) Pulsed field-ionization photoelectron-photoion coincidence study of the process $\mathrm{N}_{2}+\mathrm{hv} \rightarrow \mathrm{N}^{+}+\mathrm{N}+\mathrm{e}^{-}$: bond dissociation energies of $\mathrm{N}_{2}$ and $\mathrm{N}_{2}^{+}$. J Chem Phys 123:074330

65. Gaydon AG (1968) Dissociation energies and spectra of diatomic molecules, 3rd edn. Chapman and Hall, London, pp 184-196

66. Brix P, Herzberg G (1954) Fine structure of the SchumannRunge bands near the convergence limit and the dissociation energy of the oxygen molecule. Can J Phys 32:110-135

67. Lewis BR, Berzins L, Carver JH, Gibson ST (1985) Decomposition of the photo absorption continuum underlying the Schumann-Runge bands of ${ }^{16} \mathrm{O}_{2}$. I. Role of the $\mathrm{B}^{3} \Sigma_{\mathrm{u}}^{-}$state: a new dissociation limit. J Quant Spectrosc Radiat Transfer 33:627-643

68. Martin JDD, Hepburn JW (1997) Electric field induced dissociation of molecules in Rydberg-like highly vibrationally excited ion-pair states. Phys Rev Lett 79:3154-3157

69. Gibson ST, Lewis BR, Baldwin KG, Carver JH (1991) Rotational features in the fluorescence excitation spectrum of $\mathrm{O}\left({ }^{1} \mathrm{D}_{2}\right)$ from vacuum ultraviolet laser photodissociation of $\mathrm{O}_{2}$. J Chem Phys 94:1060-1068

70. Cosby PC, Huestis DL (1992) On the dissociation energy of $\mathrm{O}_{2}$ and the energy of the $\mathrm{O}_{2}^{+}$b ${ }^{4} \Sigma_{\mathrm{g}}^{-}$state. J Chem Phys 97:6108-6112

71. Herzberg G (1950) Molecular spectra and molecular structure. I. Spectra of diatomic molecules, 2nd edn. Van Nostrand, Princeton, NJ

72. Colbourn EA, Dagenais M, Douglas AE, Raymonda JW (1976) The electronic spectrum of $F_{2}$. Can J Phys 54:1343-1359

73. Ruscic B, Feller D, Dixon DA, Peterson KA, Harding LB, Asher RL, Wagner AF (2001) Evidence for a lower enthalpy of formation of hydroxyl radical and a lower gas-phase bond dissociation energy of water. J Phys Chem A 105:1-4

74. Ruscic B, Wagner AF, Harding LB, Asher RL, Feller D, Dixon DA, Peterson KA, Song Y, Qian X, Ng C-Y, Liu J, Chen W, Schwenke DW (2002) On the enthalpy of formation of hydroxyl 
radical and gas-phase bond dissociation energies of water and hydroxyl. J Phys Chem A 106:2727-2747

75. Barna D, Nagy B, Csontos J, Császár AG, Tasi G (2009) Benchmarking experimental and computational thermochemical data: a case study of the butane conformers. J Chem Theor Comput 8:479-486

76. Bytautas L, Ruedenberg K (2009) Ab initio potential energy curve of $\mathrm{F}_{2}$. IV. Transition from the covalent to the van der Waals region: competition between multipolar and correlation forces. J Chem Phys 130:204101

77. Yang J, Hao Y, Li J, Zhou C, Mo Y (2005) A combined zero electronic kinetic energy spectroscopy and ion-pair dissociation imaging study of the $\mathrm{F}_{2}{ }^{+}\left(\mathrm{X}^{2} \Pi_{\mathrm{g}}\right)$ structure. J Chem Phys 122:134308

78. Yang J, Hao Y, Li J, Zhou C, Mo Y (2007) Erratum: a combined zero electronic kinetic energy spectroscopy and ion-pair dissociation imaging study of the $\mathrm{F}_{2}{ }^{+}\left(\mathrm{X}^{2} \Pi_{\mathrm{g}}\right)$ structure. J Chem Phys 127:209901

79. Bytautas L, Matsunaga N, Nagata T, Gordon MS, Ruedenberg K (2007) Accurate ab initio potential energy curve of $F_{2}$. III. The vibration rotation spectrum. J Chem Phys 127:204313

80. Csontos B, Nagy B, Csontos J, Kállay M (2013) Dissociation of the fluorine molecule. J Phys Chem A 117:5518-5528 